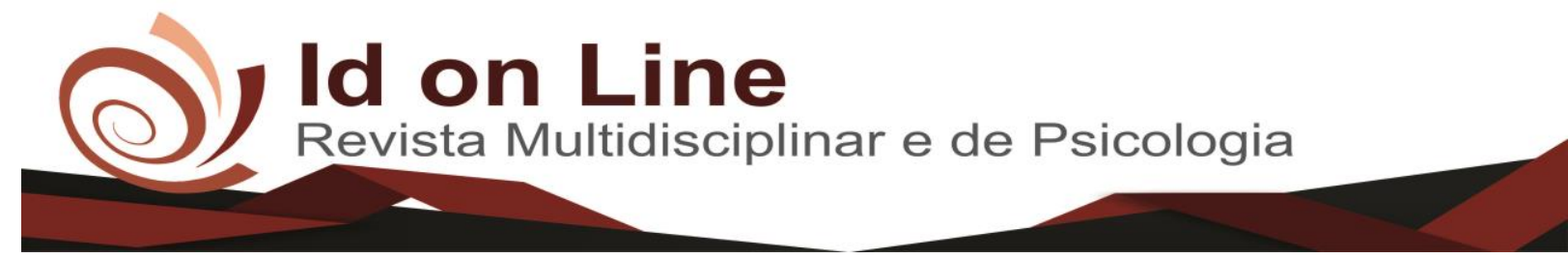

Artigo

\title{
Sintomas Depressivos em Enfermeiros do Serviço Hospitalar Privado
}

\author{
Alisson Aparecido da Luz ; Denise de Faria Lima²; Amanda Aparecida Borges ${ }^{3}$; \\ Vanessa Oliveira Silva Pereira ${ }^{4}$ :Mateus Goulart Alves ${ }^{5}$; Maria Celia Barcellos Dalri ${ }^{6}$
}

\begin{abstract}
Resumo: Riscos de adoecimento com desenvolvimento de sintomas depressivos deve ser avaliados em enfermeiros independentemente do local de atuação. Poucos são os estudos observados sobre sintomas depressivos em enfermeiros no contexto hospitalar privado. O objetivo desta pesquisa é investigar sintomas depressivos em enfermeiros que atuam em Hospital privado. Trata-se de um estudo de caráter descritivo, exploratório e transversal, com abordagem quantitativa. Dados analisados através de estatística descritiva. Os participantes foram 22 enfermeiros de um hospital privado do interior de Minas Gerais. A coleta de dados foi por meio do Inventário de Depressão de Beck. Observou-se 70\% sem depressão ou depressão mínima; 30\% em nível de depressão leve a moderada. Mesmo sem índices de depressão grave é possível verificar a inclinação da enfermagem atuante em hospital privado à depressão, reforçando a necessidade de programas institucionais e estudos que avaliem as possibilidades de alcance no equilíbrio da saúde psíquica do enfermeiro.
\end{abstract}

Palavras Chave: Depressão; Enfermeiras e Enfermeiros; Hospitais Privados.

\section{Depressive Symptoms in Nurses of the Private Hospital Service}

\begin{abstract}
Risks of illness with development of depressive symptoms should be evaluated in nurses regardless of their place of performance. There are few studies on depressive symptoms observed in nurses in the private hospital context. The objective of this research is to investigate depressive symptoms in nurses who work in private hospitals. This is a descriptive, exploratory and cross-sectional study, with a quantitative approach. Data analyzed through descriptive statistics. Participants were 22 nurses from a private hospital in the interior of Minas Gerais. Data collection was through the Beck Depression Inventory. It was observed $70 \%$ without depression or minimal depression; $30 \%$ at the level of mild to moderate depression. Even without severe depression rates, it is possible to verify the inclination of private hospital nursing to depression, reinforcing the need for institutional programs and studies that evaluate the possibilities of reaching the equilibrium of the psychic health of the nurse.
\end{abstract}

Keywords: Depression; Nurses and Nurses; Private Hospitals.

\footnotetext{
${ }^{1}$ Enfermeiro. Egresso da Universidade do Estado de Minas Gerais | Unidade Passos. E-mail: alisson.luz @hotmail.com. Passos (MG), Brasil. Contato: alisson.luz@ hotmail.com;

${ }^{2}$ Enfermeira. Egressa da Universidade do Estado de Minas Gerais | Unidade Passos. E-mail: deniseflima@ hotmail.com. Passos (MG), Brasil. Contato: deniseflima@ @otmail.com;

${ }^{3}$ Mestre. Programa em Enfermagem da Universidade de São Carlos. Docente na Universidade do Estado de Minas Gerais | Unidade Passos. E-mail: amanda.borges@uemg.br. Passos (MG), Brasil. Contao: amanda.borges@uemg.br;

${ }^{4}$ Mestre. Programa de Mestrado Profissional de Tecnologia e Inovação em Enfermagem, Escola de Enfermagem de Ribeirão Preto, Universidade de São Paulo/USP. Docente na Universidade do Estado de Minas Gerais | Unidade Passos. E-mail: vanessa.pereira@uemg.br. Passos (MG), Brasil. Contato: vanessa.pereira@uemg.br;

${ }_{5}^{5}$ Mestre. Programa de Mestrado em Enfermagem Fundamental - Nível Mestrado Acadêmico, Escola de Enfermagem de Ribeirão Preto, Universidade de São Paulo/USP. Docente na Universidade do Estado de Minas Gerais | Unidade Passos e Faculdade Atenas | Campus Passos. E-mail: mateus.alves@uemg.br. Passos (MG), Brasil.

${ }^{5}$ Doutora. Docente na Escola de Enfermagem de Ribeirão Preto, Universidade de São Paulo/USP. E-mail: macdalri@eerp.usp.br. Ribeirão Preto (SP), Brasil. Contato: macdalr@eerp.usp.br.
} 


\section{Introdução}

Os profissionais de enfermagem enfrentam diariamente inúmeras situações geradoras de estresse, ansiedade e é constante o risco de desenvolver doenças psiquiátricas, como a depressão.

Os profissionais de enfermagem lidam com a existência de fatores específicos que contribuem para o aparecimento de estresse, como a desvalorização do trabalho, divisões de tarefas em categorias, relação autoritária com subordinados, com os pacientes e equipe e, muitas vezes, ainda com a relação submissa ao poder do médico. Cuidar e gerenciar são as funções do enfermeiro e, algumas vezes, ausência de boa comunicação com a equipe multiprofissional e a competição entre os profissionais acarretam o estresse e depressão (OLIVEIRA, 2015).

Dependendo do ambiente em que o profissional de enfermagem atua, o ambiente pode estimular o estresse e comprometendo assim a saúde dos profissionais de enfermagem pelas suas exposições a riscos psicossociológicos. O meio de trabalho na enfermagem possui uma carga de estresse excessiva, fato que pode atingir a qualidade de vida do profissional e leva-lo ao adoecimento (OLIVEIRA; MAZZAIA; MARCOLAN, 2015).

Segundo a Organização Mundial da Saúde (OMS), o estresse é um dos principais motivos que causa acidentes de trabalho no mundo, representando $25 \%$ das notificações de afastamento por invalidez. O Brasil perde somente para o Japão em número de trabalhadores vítimas de problemas psicológicos (ORGANIZAÇÃO INTERNACIONAL DO TRABALHO, 2009).

Os sintomas de depressão são destacados desde a antiguidade (500 a.C - 100 d.C), na época era conhecida como melancolia, com os sintomas de desejo de morte, falta de apetite e tristeza. Depois com o tempo e os avanços biológicos foi identificado que a melancolia era um subtipo de depressão. (DUAILIB; SILVA; JUBARA 2015).

A depressão pode surgir pelas situações desagradáveis presentes no cotidiano de uma pessoa, devido a algum tipo de perda, frustações ou alguns momentos vivenciais que atinge o seu psicológico. Podendo vir acompanhada de ansiedade, baixa estima e a representação negativa de tudo que vivencia (GARRO; CAMILO; NOBREGA 2016). 
É indispensável que a saúde psíquica do enfermeiro esteja preservada, visto que, a insistência e permanência na atuação do profissional adoecido ou em processo de adoecimento, resultarão em implicações para o profissional, instituição e pacientes.

Portanto, é necessário que sejam identificados os sintomas de depressão precocemente e, desta forma, sejam promovidas ações de promoção, prevenção e recuperação nos profissionais atuantes nos serviços de enfermagem.

Vários são os estudos relevantes que discorrem sobre a saúde mental dos profissionais que exercem suas atividades no sistema público, apesar disso, raros são os que abordam o perfil dos trabalhadores da saúde em serviços privados.

Este estudo tem como objetivo levantar e classificar os sintomas de depressão através do Inventário de Depressão de Beck em enfermeiros de um serviço hospitalar privado de uma cidade do interior de Minas Gerais.

\section{Metodologia}

A presente pesquisa trata-se de um estudo de caráter descritivo, exploratório e transversal, com abordagem quantitativa, realizada em um hospital privado em uma cidade do interior de Minas Gerais.

Este estudo contou com a participação de 20 enfermeiros, sendo utilizado como critério de inclusão os enfermeiros que atuam no hospital privado por, pelo menos, três meses, e como critérios de exclusão os profissionais enfermeiros em período de férias ou afastamento e aqueles já diagnosticados com depressão ou em uso de psicotrópicos continuamente no período de coleta de dados. Foram convidados a participar da pesquisa todos os enfermeiros que atuam no local de estudo, ou seja, 22 enfermeiros, porém, seguindo os critérios de inclusão e exclusão, apenas 20 enfermeiros participaram da pesquisa.

Como instrumento para coleta de dados, foi utilizado o Inventário de Depressão de Beck (IDB) que avalia os níveis de depressão. O IDB tem estrutura composta por 21 itens, que inclui sintomas e atitudes depressivas dos últimos 15 dias, cuja intensidade varia de 0 a 3 . A classificação dos níveis segue os seguintes valores: 0 a 13 sem depressão ou depressão mínima; 14 a 19 com depressão leve; 20 a 28, depressão moderada; e 29 a 63 com depressão grave. 
Referindo-se à Perda de Interesse por Sexo; Cansaço ou Fadiga; Dificuldade de Concentração; Alteração de Apetite; Irritabilidade; Alterações no Padrão do Sono; Falta de Energia; Desvalorização; Indecisão; Perda de Interesse; Agitação; Choro; Pensamentos Suicidas; Autocritica; Autoestima; Sentimentos de Punição; Sentimento de Culpa; Perda de Prazer; Fracasso; Pessimismo; Tristeza.

Segundo Wang e Gorenstein (2013) o IDB é um instrumento relevante que demonstra fidelidade e eficácia ao distinguir indivíduos não deprimidos e deprimidos. O IDB é um questionário confiável e de baixo custo, tem destaque para pesquisa e prática clínica em todo o mundo.

Foi enviado solicitação à autora responsável pela validação em língua portuguesa para autorização de aplicação do IDB neste estudo e segundo orientação da mesma, foram adotados os critérios por ser um instrumento protegido por direitos autorais, adquirindo os formulários com o grupo Pearson Clinical Brasil.

Os dados foram coletados no mês de agosto do ano de 2017 em data e horário definidos pelos participantes. Para abordagem individual foi utilizada sala reservada, disponibilizada pelo hospital, onde houve orientações a respeito dos objetivos e importância da pesquisa e, também, sobre a relevância do instrumento psicométrico, IDB. Após, foi realizada leitura e, em concordância, assinatura do Termo de Consentimento Livre e Esclarecido (TCLE). Para tranquilidade em responder os 21 itens do IDB, os pesquisadores ausentaram da sala, em média de 30 minutos, para que fossem respondidos todos itens. A pesquisa contou como auxiliar de pesquisa, uma psicóloga, pois o IDB é de aplicação exclusiva desta categoria profissional.

A análise dos dados desenvolveu-se a partir de análise descritiva simples e apresentado por meio de gráficos e tabelas em números e percentagem.

O presente estudo foi submetido ao Comitê de Ética em Pesquisa (CEP) da Fundação de Ensino Superior de Passos, sob o CAAE: 69060917.8.0000.5112, em obediência a resolução brasileira do Conselho Nacional de Saúde (CNS) nº 466/12 que dispõe sobre as Diretrizes e Normas Regulamentadoras de Pesquisas envolvendo Seres Humanos, obtendo parecer favorável. 


\section{Resultados}

A seguir, estão organizados os resultados dos dados coletados. Divididos em três grupos: Características dos Enfermeiros; Distribuição dos Grupos de Afirmações e Distribuição da Classificação do Nível de Depressão de acordo com IDB.

Tabela 1 - Características dos enfermeiros quanto ao local de atuação, sexo, idade e tempo de atuação em Hospital Privado. Passos, Minas Gerais, Brasil, 2017.

\begin{tabular}{lcc}
\hline Local de atuação & n & $\%$ \\
Unidades de Clínica Médica & 08 & 40 \\
Unidade de Terapia Intensiva & 04 & 20 \\
Unidade de Pronto Atendimento & 04 & 20 \\
Serviço de Controle de Infecção Hospitalar & 01 & 05 \\
Gerência & 01 & 05 \\
Bloco Cirúrgico & 02 & 10 \\
Sexo & & \\
Masculino & 01 & 05 \\
Feminino & 19 & 95 \\
Idade & \\
Média em anos & 32,7 \\
Tempo de Atuação em Hospital Privado & \\
Média em anos & 3,65 \\
\hline Fon: Pesquisa dos autes
\end{tabular}

Fonte: Pesquisa dos autores

Nota-se a partir da Tabela 1 que os profissionais estão divididos em: 08 (40\%) exercem suas funções em unidades de Clínica Médica; 04 (20\%) estão na UTI; 04(20\%) no Pronto Atendimento; 01 (5\%) atuam no Controle de Infecção Hospitalar; 01(5\%) responsável pela Gerência e 02 (10\%) representam o Bloco Cirúrgico.

Em relação ao sexo, há uma predominância 19 (95\%) de profissionais do sexo feminino sobre o sexo masculino 01 (5\%), idade média de 32,7 anos. No que se refere ao tempo de atuação em hospital privado, a média, em anos, representada foi de 3,65.

A Tabela 2, apresentada a seguir, demonstra os resultados de acordo com os 21 itens compostos no IDB, sendo eles: Perda de Interesse por Sexo; Cansaço ou Fadiga; Dificuldade de Concentração; Alteração de Apetite; Irritabilidade; Alterações no Padrão do Sono; Falta de Energia; Desvalorização; Indecisão; Perda de Interesse; Agitação; Choro; Pensamentos Suicidas; Autocrítica; Autoestima; Sentimentos de Punição; Sentimento de Culpa; Perda de Prazer; Fracasso; Pessimismo; Tristeza. 
Tabela 2 - Distribuição dos grupos de afirmações de acordo com os itens e grupo de afirmações do Inventário de Depressão de Beck de acordo com as respostas dos participantes. Passos, Minas Gerais, Brasil, 2017.

\begin{tabular}{|c|c|c|}
\hline & $\mathbf{n}$ & $\%$ \\
\hline \multicolumn{3}{|l|}{ Tristeza } \\
\hline O Não me sinto triste. & 18 & 90 \\
\hline 1 Eu me sinto triste grande parte do tempo. & 2 & 10 \\
\hline 2 Estou triste o tempo todo. & 0 & 0 \\
\hline 3 Estou tão triste ou tão infeliz que não consigo suportar. & 0 & 0 \\
\hline \multicolumn{3}{|l|}{ Pessimismo } \\
\hline O Não estou desanimado(a) a respeito do meu futuro. & 17 & 85 \\
\hline 1 Eu me sinto mais desanimado(a) a respeito do meu futuro do que de costume. & 3 & 15 \\
\hline 2 Não espero que as coisas dêem certo para mim. & 0 & 0 \\
\hline 3 Sinto que não há esperança quanto ao meu futuro. Acho que só vai piorar. & 0 & 0 \\
\hline \multicolumn{3}{|l|}{ Fracasso passado } \\
\hline o Não me sinto um(a) fracassado(a). & 19 & 95 \\
\hline 1 Tenho fracassado mais do que deveria. & 1 & 5 \\
\hline 2 Quando penso no passado vejo muitos fracassos. & 0 & 0 \\
\hline 3 Sinto que como pessoa sou um fracasso total. & 0 & 0 \\
\hline \multicolumn{3}{|l|}{ Perda do prazer } \\
\hline o Continuo sentindo o mesmo prazer que sentia com as coisas que eu gosto. & 9 & 45 \\
\hline 1 Não sinto tanto prazer com as coisas como costumava sentir. & 11 & 55 \\
\hline 2 Tenho pouco prazer nas coisas que eu costumava gostar. & 0 & 0 \\
\hline 3 Não tenho mais nenhum prazer nas coisas que costumava gostar. & 0 & 0 \\
\hline \multicolumn{3}{|l|}{ Sentimento de culpa } \\
\hline O Não me sinto particularmente culpado(a). & 20 & 100 \\
\hline 1 Eu me sinto culpado(a) a respeito de várias coisas que fiz elou deveria ter feito. & 0 & 0 \\
\hline 2 Eu me sinto culpado(a) a maior parte do tempo. & 0 & 0 \\
\hline 3 Eu me sinto culpado(a) o tempo todo. & 0 & 0 \\
\hline \multicolumn{3}{|l|}{ Sentimentos de punição } \\
\hline O Não sinto que estou sendo punido(a). & 19 & 95 \\
\hline 1 Sinto que posso ser punido(a). & 1 & 5 \\
\hline 2 Eu acho que serei punido(a). & 0 & 0 \\
\hline 3 Sinto que estou sendo punido( $(a)$ & 0 & 0 \\
\hline \multicolumn{3}{|l|}{ Autoestima } \\
\hline O Eu me sinto como sempre me senti em relação a mim mesmo(a). & 20 & 100 \\
\hline 1 Perdi a confiança em mim mesmo(a). & 0 & 0 \\
\hline 2 Estou desapontado(a) comigo mesmo(a). & 0 & 0 \\
\hline 3 Não gosto de mim. & 0 & 0 \\
\hline \multicolumn{3}{|l|}{ Autocrítica } \\
\hline o Não me critico nem me culpo mais do que o habitual. & 11 & 55 \\
\hline 1 Estou sendo mais crítico(a) comigo mesmo(a) do que costumava ser. & 9 & 45 \\
\hline 2 Eu me critico por todos os meus erros. & 0 & 0 \\
\hline 3 Eu me culpo por tudo de ruim que acontece. & 0 & 0 \\
\hline \multicolumn{3}{|l|}{ Pensamentos ou desejos suicidas } \\
\hline O Não tenho nenhum pensamento de me matar. & 19 & 95 \\
\hline 1 Tenho pensamentos de me matar, mas não levaria isso adiante. & 1 & 5 \\
\hline 2 Gostaria de me matar. & 0 & 0 \\
\hline 3 Eu me mataria se tivesse oportunidade. & 0 & 0 \\
\hline \multicolumn{3}{|l|}{ Choro } \\
\hline O Não choro mais do que chorava antes. & 18 & 90 \\
\hline 1 Choro mais agora do que costumava chorar. & 2 & 10 \\
\hline 2 Choro por qualquer coisinha. & 0 & 0 \\
\hline 3 Sinto vontade de chorar, mas não consigo. & 0 & 0 \\
\hline Agitação & & \\
\hline
\end{tabular}




\begin{tabular}{|c|c|c|}
\hline O Não me sinto mais inquieto(a) ou agitado(a) do que me sentia antes. & 10 & 50 \\
\hline 1 Eu me sinto mais inquieto(a) ou agitado(a) do que me sentia antes. & 9 & 45 \\
\hline 2 Eu me sinto tão inquieto(a) ou agitado(a) que é difícil ficar parado(a). & 0 & 0 \\
\hline 3 Estou tão inquieto(a) ou agitado(a) que tenho que estar sempre me mexendo ou fazendo alguma coisa. & 1 & 5 \\
\hline \multicolumn{3}{|l|}{ Perda de interesse } \\
\hline O Não perdi o interesse por outras pessoas ou por minhas atividades. & 14 & 70 \\
\hline 1 Estou menos interessado(a) pelas outras pessoas ou coisas do que costumava estar. & 6 & 30 \\
\hline 2 Pedi quase todo o interesse por outras pessoas ou coisas. & 0 & 0 \\
\hline 3 É difícil me interessar por alguma coisa. & 0 & 0 \\
\hline \multicolumn{3}{|l|}{ Indecisão } \\
\hline \multicolumn{3}{|l|}{ O Tomo minhas decisões tão bem quanto antes. } \\
\hline \multicolumn{3}{|l|}{1 Acho mais difícil tomar as decisões agora do que antes. } \\
\hline \multicolumn{3}{|l|}{2 Tenho muito mais dificuldade em tomar decisões agora do que antes. } \\
\hline \multicolumn{3}{|l|}{3 Tenho dificuldade para tomar qualquer decisão. } \\
\hline \multicolumn{3}{|l|}{ Desvalorização } \\
\hline O Não me sinto sem valor. & 11 & 55 \\
\hline 1 Não me considero hoje tão útil ou não me valorizo como antes. & 9 & 45 \\
\hline 2 Eu me sinto com menos valor quando me comparo com outras pessoas. & 0 & 0 \\
\hline 3 Eu me sinto completamente sem valor. & 0 & 0 \\
\hline \multicolumn{3}{|l|}{ Falta de energia } \\
\hline 0 Tenho tanta energia hoje como sempre tive. & 10 & 50 \\
\hline 1 Tenho menos energia do que costumava ter. & 9 & 45 \\
\hline 2 Não tenho energia suficiente para fazer muita coisa. & 1 & 5 \\
\hline 3 Não tenho energia suficiente para nada. & 0 & 0 \\
\hline \multicolumn{3}{|l|}{ Alterações no padrão de sono } \\
\hline O Não percebi nenhuma mudança no meu sono. & 9 & 45 \\
\hline $\begin{array}{l}\text { la Durmo um pouco mais do que o habitual. } \\
\text { Ib Durmo um pouco menos do que o habitual. }\end{array}$ & 10 & 50 \\
\hline $\begin{array}{l}\text { 2a Durmo muito mais do que o habitual. } \\
2 b \text { Durmo muito menos do que o habitual. }\end{array}$ & 1 & 5 \\
\hline $\begin{array}{l}3 \text { a Durmo a maior parte do dia. } \\
3 \text { b Acordo } 1 \text { ou } 2 \text { horas mais cedo e não consigo voltar a dormir. }\end{array}$ & 0 & 0 \\
\hline \multicolumn{3}{|l|}{ Irritabilidade } \\
\hline O Não estou mais irritado(a) do que o habitual. & 7 & 35 \\
\hline 1 Estou mais irritado(a) do que o habitual. & 12 & 60 \\
\hline 2 Estou muito mais irritado(a) do que o habitual. & 0 & 0 \\
\hline 3 Fico irritado(a) o tempo todo. & 1 & 5 \\
\hline \multicolumn{3}{|l|}{ Alterações de apetite } \\
\hline O Não percebi nenhuma mudança no meu apetite. & 13 & 65 \\
\hline $\begin{array}{l}\text { la Meu apetite está um pouco menos do que o habitual. } \\
1 \text { (b Meu apetite está um pouco maior do que o habitual. }\end{array}$ & 6 & 30 \\
\hline $\begin{array}{l}2 \text { a Meu apetite está muito menor do que antes. } \\
2 b \text { Meu apetite está muito maior do que antes. }\end{array}$ & 1 & 5 \\
\hline $\begin{array}{l}3 \text { a Não tenho nenhum apetite. } \\
3 \text { b Quero comer o tempo todo. }\end{array}$ & 0 & 0 \\
\hline \multicolumn{3}{|l|}{ Dificuldade de concentração } \\
\hline 0 Posso me concentrar tão bem quanto antes. & 5 & 25 \\
\hline 1 Não posso me concentrar tão bem como habitualmente. & 11 & 55 \\
\hline 2 É muito difícil manter a concentração em alguma coisa por muito tempo. & 2 & 10 \\
\hline 3 Eu acho que não consigo me concentrar em nada. & 2 & 10 \\
\hline \multicolumn{3}{|l|}{ Cansaço ou fadiga } \\
\hline o Não estou mais cansado(a) ou fatigado(a) do que o habitual. & 10 & 50 \\
\hline 1 Fico cansado(a) ou fatigado(a) mais facilmente do que o habitual. & 8 & 40 \\
\hline 2 Eu me sinto muito cansado(a) ou fatigado(a) para fazer muitas coisas que costumava fazer. & 2 & 10 \\
\hline 3 Eu me sinto muito cansado(a) ou fatigado(a) para fazer a maioria das coisas que costumava fazer. & 0 & 0 \\
\hline \multicolumn{3}{|l|}{ Perda de interesse por sexo } \\
\hline O Não notei qualquer mudança recente no meu interesse por sexo. & 10 & 50 \\
\hline 1 Estou menos interessado(a) em sexo do que costumava estar. & 8 & 40 \\
\hline 2 Estou muito menos interessado(a) em sexo agora. & 2 & 10 \\
\hline
\end{tabular}


Fonte: Pesquisa dos autores

A análise do fator TRISTEZA demonstrou que nenhum participante se sente tão triste ou tão infeliz que não consegue suportar ou está triste o tempo todo; 02 (10\%) se sentem triste grande parte do tempo e 18 (90\%) não se sentem triste.

Relativo ao PESSIMISMO ninguém refere que não a esperança quanto ao futuro ou não esperam que as coisas dêem certo; 03 (15\%) não se sentem mais desanimados a respeito do futuro como de costume e 17(85\%) não estão desanimados a respeito do futuro.

Quanto ao FRACASSO PASSADO, não houve sentimentos que como pessoa se sentem um fracasso ou quando pensam no passado veem muitos fracassos; 01(5\%) tem fracassado mais do que deveria e 19(95\%) não se sentem um fracassado.

Tendo em consideração a PERDA DE PRAZER ninguém acredita não ter mais nenhum prazer nas coisas que costumavam fazer ou tem muito pouco prazer nas coisas que costumava fazer; $11(55 \%)$ não sentem tanto prazer com as coisas como costumavam sentir e 09 (45\%) continuam sentindo o mesmo prazer que sentiam com as coisas que gostam.

Sobre os sentimentos de CULPA os participantes não se sentem culpados o tempo todo ou não se sentem culpados a maior parte do tempo ou se sentem culpados a respeito de várias coisas que fez ou que deveria ter feito e 20 (100\%) não se sentem particularmente culpados.

Os fatores relacionados ao SENTIMENTO DE PUNIÇÃO apontam que nenhum participante não sente estar sendo punido ou que serão punidos; 01(5\%) sentem que podem ser punidos e 19 (95\%) não sentem que estão sendo punidos.

A item sobre AUTOESTIMA indica que ninguém sente não gostar de si ou estar desapontado consigo mesmo ou ter perdido a confiança em si mesmo e 20 (100\%) se sentem como sente se sentiram em relação a si mesmo.

Quanto a AUTOCRÍTICA não foi indicado que se culpam por tudo de ruim que acontecem ou que se criticam por todos seus erros;09(45\%) estão sendo mais críticos consigo mesmo do que costumavam ser e 11 (55\%) não se criticam ou se culpam mais do que o habitual.

Correspondente as afirmativas sobre PENSAMENTOS OU DESEJOS SUICIDAS ninguém se mataria se tivesse oportunidade ou gostaria de se matar; $01(5 \%)$ tem pensamentos de se matar mas não levaria isso adiante e 19 (95\%) não tem nenhum pensamento de se matar. 
Com relação ao CHORO, não foi selecionado a alternativa sente vontade de chorar, mas não consegue ou chora por qualquer coisinha; 02 (10\%) choram mais agora do que acostumavam chorar; 18 (90\%) não choram mais do que choravam antes.

Ao avaliar a AGITAÇÃO, nota-se que 01 (5\%) estão tão inquietos ou agitados que precisam estar sempre se mexendo ou fazendo alguma coisa; ninguém se sente tão inquieto ou agitado que é difícil ficar parado; 09 (45\%) se sentem mais inquietos ou agitados do que se sentiam antes e 10 (50\%) não se sentem mais inquietos ou agitados do que se sentiam antes.

Em análise o item PERDA DE INTERESSE os profissionais não consideram difícil se interessar por alguma coisa ou perdeu quase todo o interesse por outras pessoas ou coisas; 06 $(30 \%)$ estão menos interessados pelas outras pessoas ou coisas do que costumavam estar; 14 (70\%) não perderam o interesse por outras pessoas ou por suas atividades.

Considerando a INDECISÃO, nenhum enfermeiro tem dificuldade para tomar qualquer decisão, tem muito mais dificuldade de tomar decisões agora do que antes ou acha mais difícil tomar decisões agora do que antes e 20 (100\%) tomam decisões tão bem quanto antes.

O item DESVALORIZAÇÃO demonstra que ninguém se sente completamente sem valor ou se sente com menos valor quando se compara com outras pessoas; 09(45\%) não se consideram hoje tão útil ou não se valorizam como antes e 11 (55\%) não se sentem sem valor.

Ao observar o item FALTA DE ENERGIA, os participantes não sentem que não tem energia suficiente para nada; $01(5 \%)$ não têm energia para fazer muita coisa;09(45\%) têm menos energia do que costumava ter e $10(50 \%)$ tem tanta energia hoje como sempre teve.

Relativo às alterações no PADRÃO DE SONO, não foi selecionada a alternativa que afirma que: dormem a maior parte do dia ou acordam uma ou duas horas e não conseguem voltar a dormir; 01 (5\%) dormem muito menos ou muito mais do que o habitual; 09 (45\%) não perceberam nenhuma mudança no sono e 10 (50\%) dormem pouco menos ou pouco mais do que o habitual; 01 (5\%) dormem muito menos ou muito mais do que o habitual.

Tendo em consideração o item IRRITABILIDADE os participantes não se consideraram muito mais irritados do que o habitual; 01 (5\%) ficam irritados o tempo todo; 07 (35\%) não estão mais irritados do que o habitual e 12 (60\%) percebem estar mais irritados do que o habitual

Quanto à ALTERAÇÃO DE APETITE, nenhuma pessoa considera que quer comer o tempo todo; 01 (5\%) afirmaram muita mudança no apetite habitual (menor ou maior); 06 (30\%) 
perceberam pouca mudança no apetite habitual (menor ou maior) e 13 (65\%) demonstraram não perceber nenhuma mudança no apetite.

Sobre a DIFICULDADE DE CONCENTRAÇÃO, 02 (10\%) apontam que é muito difícil manter a concentração em alguma coisa por muito tempo e02(10\%) acham que não consegue se concentrar em nada; 05 (25\%) dos enfermeiros não se concentram tão bem como antes; 11 (55\%) não podem concentrar tão bem como habitualmente.

Segundo o item CANSAÇO E FADIGA nenhum se sente muito cansado ou fatigado para fazer a maioria das coisas que costumavam fazer; 02(10\%) indicam que se sentem cansados ou fadigados para fazer muitas coisas que costumavam fazer; 08 (40\%) sentem- se cansados ou fadigados mais facilmente do que o habitual e $10(50 \%)$ não se sentem mais cansados ou fadigados do que o habitual.

Em relação à PERDA DE INTERESSE PELO SEXO ninguém considera ter perdido completamente o interesse pelo sexo; 02 (10\%) estão muito menos interessados em sexo agora; $08(40 \%)$ consideram-se menos interessados pelo sexo do que costumavam estar; $10(50 \%)$ dos profissionais de enfermagem não notaram qualquer mudança recente no interesse pelo sexo.

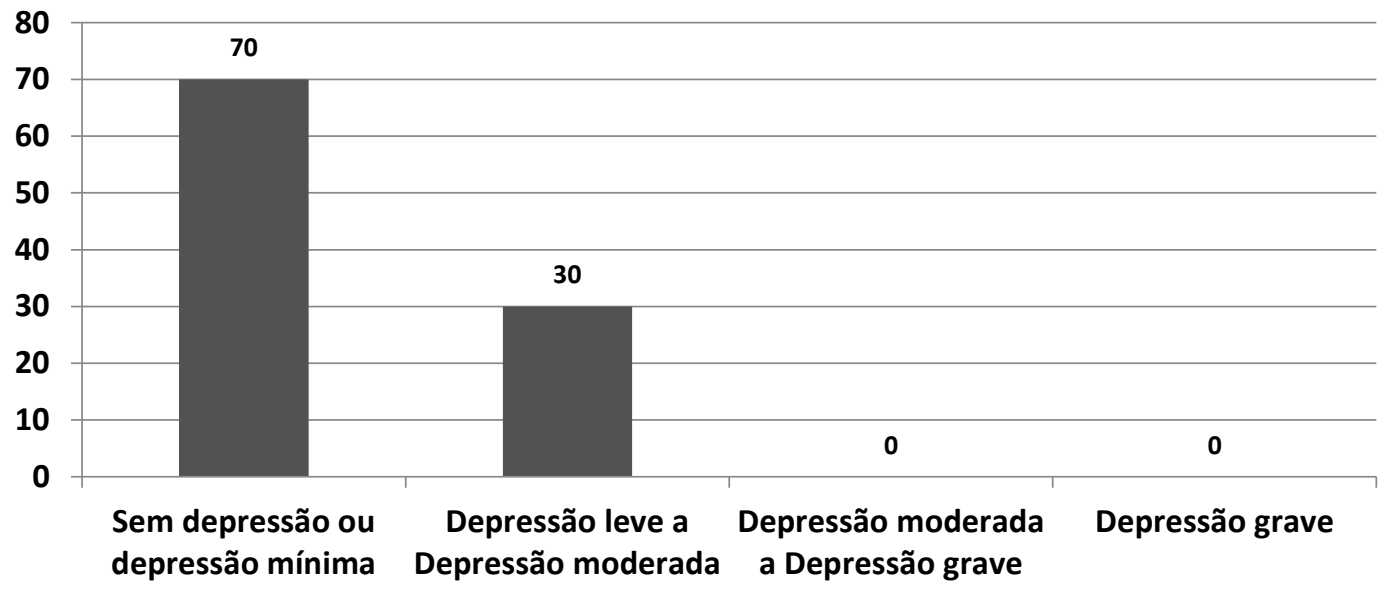

Gráfico 1 - Distribuição da Classificação do Nível de Depressão através do Inventário de Depressão de Beck de acordo com as respostas dos participantes. Passos, Minas Gerais, Brasil, 2017.

Tendo em consideração o Gráfico 1, estão representados a distribuição dos quatro níveis de depressão através do IDB. Sendo interpretado de acordo com as respostas dos participantes, temos as seguintes porcentagens: 70\% Sem depressão ou depressão mínima; 30\% em nível de 
depressão leve a moderada; sem registro de níveis de depressão moderada a depressão grave e/ou depressão grave

\section{Discussão}

Baseado em uma abordagem sociológica, Vegro et al. (2016) acreditam que as instituições sofrem muitos tipos de influências, desde influências do mercado externo até as opiniões de seus respectivos membros, que carregam diversas estórias, contexto, moral, conceitos e subjetividades.

De acordo com Fernandes e Mercolan (2017), a dura realidade do serviço de saúde ocasiona sofrimento psíquico, favorecendo o surgimento de significativos sintomas depressivos nos enfermeiros. Além disso, aponta que os enfermeiros não percebem ou admitem ter sintomas depressivos, e, as raras exceções apontam para as condições de trabalho como estimulador do adoecimento.

Segundo Santos et al. (2017), as pressões que acometem os profissionais da saúde em serviços privado ou público são similares. Contudo, estudos demonstraram que no ambiente hospitalar privado existem mecanismos que auxiliam aos profissionais lidar de modo mais efetivo com os eventos de sofrimento e desgaste ao qual são frequentemente expostos, além de apresentar melhores práticas para exercer as atividades necessárias.

Assim, aspectos relacionados ao meio de trabalho são capazes de estar diretamente ligados a satisfação ou sofrimento do enfermeiro e é nítida a influência demonstrada, através de estudos, quando comparado o ambiente hospitalar privado do público. Porém, poucos estudos relevantes sobre o âmbito privado são feitos, voltando toda atenção ao serviço público. O que tornou necessário observação sobre a população a fim de confirmar os raros estudos.

Relacionado ao local de atuação, Preto e Pedrão (2014) afirmam que o local pode ser determinante desencadeador de elementos que constituem o desgaste psicológico. Torna-se necessário que o enfermeiro saiba reconhecer os aspectos que o incomodam para poder, de alguma forma, enfrentar tal situação.

Sales (2014) argumenta que o ambiente em que as relações interpessoais são prazerosas e produtivas, é favorável para a capacidade de rendimento profissional e traz encorajamento ao 
funcionário. No entanto, quando o local oferece situações indevidas ou precárias, envolvem não somente falhas à saúde física, mas também à saúde mental.

Podemos perceber ao relacionar os autores que a divisão justa do trabalho e número de pessoal adequado às necessidades do setor são fatores primordiais e que geram resultados sobre a saúde do profissional enfermeiro. Em todas as alas, observou-se uma justa divisão de enfermeiros e a ajuda de outros setores em casos de sobrecarga, o que é parte importante da satisfação e resultados positivos obtidos.

Conforme as ideias de Nardi, Ferreira e Neufeld (2017), a infância é uma etapa carregada de desafios. As diversas situações geradas, positivamente ou negativamente, exigem recursos para serem superadas e se as crianças não estiverem preparadas para a solução dos conflitos, poderão acarretar sintomas psicológicos e depressivos. Enquanto isso, Semedo et al. (2017) sustentam que a depressão é uma das mais comuns enfermidades que atinge os idosos. Afirmam que sendo uma patologia de etiologia indefinida o diagnóstico é complexo e ao identificar as sintomatologias precocemente, deve-se interferir de forma adequada para melhoria da qualidade de vida.

Correlacionando os autores verifica-se que a depressão não é um mal que atinge determinada média de idade. Após um trauma, luto ou situação de estresse é possível desenvolver sintomas depressivos em qualquer período da vida e carregar consigo a depressão por muitos anos, se não tratada adequadamente. Por isso, independente da faixa etária dos profissionais é necessário o cuidado e prevenção.

O desempenho sexual depende do estado psicológico, social e o contexto biológico e as relações sobre eles. Os problemas sexuais são associados a qualidade de vida tanto para homens quanto para mulheres (FLEURYI; ABDOII 2015).

Analisando a relação de perda de interesse pelo sexo como um fator importante para o diagnostico ou desenvolvimento da depressão, identifica-se que a ausência de disposição para atividades que antes eram prazerosas é elemento de preocupação e observação. O desinteresse sexual pode ser a primeira manifestação da depressão no indivíduo.

De acordo com Cruz (2014), a fadiga e o cansaço em profissionais de enfermagem estão relacionados com os sintomas de ansiedade, estresse e depressão. Na maioria dos casos esses sintomas aparecem por compaixão e autocompaixão, tanto para pacientes quanto para colegas de trabalho e a si mesmo. 
Porém Silva et al. (2016), afirmam que as causas principais da fadiga e esgotamento dos enfermeiros são a sobrecarga de serviço no turno do trabalho, a distribuição de tarefas pelos supervisores que deverão ser realizadas em um curto período de tempo e o nível de autoridade e autonomia no cenário de trabalho.

Contudo, há indícios de que toda forma de sofrimento psíquicos são fatores capazes de desenvolver a depressão. Assim, independentemente do fator que desencadeou a fadiga e o cansaço, o sofrimento decorrente dessas sensações podem ser geradoras de depressão.

De acordo com Zandoná, Cabral e Sulzbach (2014), a sobrecarga do trabalho, disputas profissionais, ritmos e rotina de trabalho, pressão e a cobrança, afetam de forma negativa a vida e saúde das pessoas, gerando adoecimento mental, ocasionando assim a falta de concentração e ausência de controle emocional.

A sobrecarga mental dos profissionais de enfermagem é induzida por aspectos próprios da profissão. Vários são os fatores de risco envolvidos na rotina do enfermeiro, a pressão de estar em contato com pessoas doentes que evoluem, muitas vezes, para sofrimento e morte, gerando a sobrecarga psíquica que prejudica seu desempenho e concentração (FERREIRA, FERREIRA, 2014).

Dessa forma, podemos perceber que o dano causado pela dificuldade ou ausência de concentração do enfermeiro é perigosa e ocasiona agravos que podem ser irreversíveis. Sendo a rotina imprevisível, ter um responsável desconcentrado é arriscado, pois, as situações de clínica ou urgência e emergência são repentinas e exigem cuidado extra.

Segundo Santos et al (2016), um dos principais sintomas de depressão é a alteração no apetite pelo fato da sensação de tristeza, além da diminuição do interesse pelo ambiente.

A alteração de apetite como indicador de depressão tem sido analisado há muitos anos. A alteração pode ser de aumento ou diminuição e até ausência do apetite, justificado este pelo desinteresse e aquele pela ansiedade ou necessidade de recompensar a insatisfação com a ingestão de alimentos.

De acordo com Silva et al. (2016) inúmeros aspectos relacionados ao tipo de ambiente contribuem para a irritabilidade dos enfermeiros, como as relações humanas de trabalho, grau elevado de exigência pelos seus supervisores, autonomia profissional e responsabilidades, que contribuem para o seu esgotamento profissional. 
Em análise, observa-se que o elemento irritabilidade pode trazer prejuízos emocionais e profissionais ao indivíduo e ao coletivo. Sabe-se que consequências são inúmeras, além de causar a insatisfação no ambiente, causa também ineficiência do cuidado prestado.

Uma intensa jornada de trabalho proporciona um desgaste e sofrimento. A busca incansável pela realização de diferentes atividades provoca no homem um aumento das cargas laborais, levando ao aparecimento de doenças emocionais, mentais e físicas. (RIBEIRO et al., 2012).

Quando um profissional trabalha no período noturno, o débito de sono exerce um impacto sobre o metabolismo e a função endócrina no organismo, ocorrendo a diminuição da glicose, sendo assim aumenta o risco de obesidade e sobrepeso (ARREAL; PONTIN, 2013).

A rotina do enfermeiro pode variar de acordo com a necessidade do setor de serviço, é explicito que os horários de descanso e sono são afetados pelas escalas e urgências do ambiente. As alterações do padrão de sono prejudicam consideravelmente o metabolismo, humor, funções fisiológicas e físicas do profissional.

Quando um trabalhador de enfermagem tem o trabalho excessivo, acarreta a diminuição de horários de repouso, sono, vida social, lazer e alimentação, e na maioria das vezes não sobra energia e tempo pra realizar, atividades com sua família e amigos, ou até mesmo especialização profissional (OLIVEIRA; MAZZAIA; MARCOLAN, 2015).

A sensação de perda de energia e consequente exaustão ao realizar pequenas atividades podem levar a sobrecarga e acarretar em outros fatores que, associados, levam a depressão grave. Por isso a necessidade de horários de lazer, descanso e numero adequado de funcionários na equipe.

De acordo com Santos (2015), o mais comum e o primeiro tipo de desvalorização profissional é do tipo salarial ou econômico. Sentir-se desvalorizado atinge o indivíduo e seus familiares e dependentes, pelo fato de colocar em risco sua sobrevivência e sua sustentação. O salário baixo impede o desenvolvimento do profissional e ele acaba tendo que desempenhar uma jornada dupla de trabalho.

As condições de trabalho da equipe de enfermagem em alguns hospitais são consideradas inadequadas e desmotivadoras se referindo ao risco de saúde, acumulo de serviços e pela distribuição social no trabalho que será refletido no psicológico dos profissionais e na qualidade de auxílio para o usuário. (BORDIGNON, 2015). 
Dentre as mais relevantes causas da desvalorização percebe-se a baixa remuneração, fato que força a busca por outra atividade remunerada, diminuindo consequentemente o tempo de lazer e assim, a qualidade de vida. Após, as condições de trabalho, a submissão e incapacidade de resolver problemas são fatores importantes na diminuição da autoestima e sentimento de valorização.

Nos dias atuais a depressão é considerada uma doença de saúde pública, evidenciada como a mais comum entre as doenças mentais, porque ela envolve uma limitação na vida pessoal gerando indecisões sobre si mesmo (ABELHA, 2014).

Segundo Proyer et al. (2012), após a formação profissional, os enfermeiros conhecem uma rotina cansativa, elas passam por um período de indecisão profissional por se sentirem exaustos e fadigadas com a sua posição profissional.

É necessário reconhecer as funções da profissão, ter boas condições de trabalho e ter adequado número de colaboradores para que as atividades sejam realizadas de modo a cumprir as expectativas do profissional e assim, a realização profissional seja conquistada. $\mathrm{O}$ funcionário realizado e bem resolvido busca sempre fazer e conhecer o máximo em todas as situações.

A depressão representa uma síndrome de desordem afetiva, um tipo de doença predominante na população em geral que prejudica o humor, pensamentos, inseguranças e perda de interesse nas atividades do dia a dia (CRUZ, 2014).

De acordo com Marquetti e Milek (2014), a perda do interesse por atividades comuns do cotidiano é um comportamento que está relacionado a depressão.

Relacionando os autores, observamos que a perda de interesse pode ser uma manifestação sugestiva de depressão. Ao analisar tal fator percebe-se que o desinteresse em realizar coisas naturais e que antes trariam satisfação, tornam-se atividade de alto desgaste e dificuldade para o depressivo.

De acordo com Oliveira, Mazzaia e Marcolan (2015), quando um enfermeiro se submete a trabalhar em mais de um emprego, ele aumenta a sua chance de erros e acidentes de trabalho, por conta da sua rotina agitada, e prejuízos a sua saúde mental e de seus colegas de trabalho.

A inquietação motora pode estar relacionada as manifestações externas de ansiedade e agitação. Correlacionando os autores fica claro que, a agitação é um traço depressivo e traz riscos e prejuízos aos profissionais, equipe e paciente. 
A prevalência depressiva entre enfermeiros requer atenção. Ao considerar que esse profissional tem contato com o sofrimento psicológico frequente de seus pacientes e familiares, estão vulneráveis a instabilidade de humor (CAMARGO; SOUSA; OLIVEIRA 2014).

Para Moll et. al (2014) entre principais sintomas da depressão pode-se destacar o choro sem razão aparente, por conta de desordens emocionais do cotidiano.

Demonstrar externamente os sentimentos é natural do ser humano. Ao estar alegre é normal o riso fácil, ao estar triste é comum o semblante descaído e choro, contudo, variações de humor ou choro sem motivo são claros sinais de insatisfação psicológica intensa e tendência depressiva.

O comportamento suicida tem a influência de fatores psicológicos, biológicos e socioambientais, geralmente em um estado avançado de depressão a pessoa sente necessidade de auto extermínio, no intuito de solucionar seus problemas psíquicos (NAVARRO, MARTINEZ, 2012).

$\mathrm{Na}$ maioria das vezes, quando uma pessoa possui transtorno mental ou psicológico incluindo depressão e não conseguem enfrentar seus problemas, acredita que a única forma de se livrar é o suicídio (ALMEIDA, 2015).

A busca incansável do enfermo é a solução dos seus problemas. Ao encontrar-se sem ajuda externa, sentindo-se sozinho e inútil, a única fuga que lhe parece viável e capaz de resolver tudo que lhe aflige é a morte. O suicídio, sempre é, portanto, expressão e sintoma de depressão.

De acordo com Guerreiro (2011), a autocrítica é quando um indivíduo tem a capacidade de fazer uma crítica de si mesmo, importunando uma análise de seus atos e maneira de agir, desse modo a pessoa identifica seus pontos fortes e fracos e a partir daí, tenta fazer uma auto correção de sua jornada existencial.

Lima e Rodrigues (2016) dizem que uma crítica e uma autocrítica negativa em uma pessoa que tem sintomas de depressão contribui para a piora estado mental.

A incapacidade de reconhecer o lado bom de cada coisa e a negatividade constante está entre os fatores indicativos de depressão. A autocrítica incessante pode trazer a sensação de fracasso, inutilidade é progressivo se não tratado adequadamente. 
A autoestima tem o significado de valorização intima, auto conceito e autoimagem que o indivíduo faz de si mesmo. Ela pode interferir na saúde mental e física de uma pessoa que tem sintomas de depressão (SCHULTHEISZ; APRILE 2013).

Guerreiro (2011), afirma que autoestima específica é quando as pessoas avaliam suas qualidades e defeitos específicos de suas habilidades, sendo assim a pessoa se vê como incapaz ou capaz.

A desvalorização, autocritica e pessimismo são relacionados à autoestima e depressão. A depreciação da autoestima pode trazer a visão de incapacidade e inutilidade pessoal e que pode acarretar graves consequências.

De acordo com Purcotes Júnior (2012), os sentimentos de tristeza, insônia, fadiga, perda de energia e sentimentos de punição demonstram predisposição ao desenvolvimento da depressão.

A sensação de culpa e autopunição são os sintomas mais intensos de depressão, que podem levar a pessoa a ter ideias suicidas ou de se sentir fracassado (OLIVEIRA; MAZZAIA; MARCOLAN, 2015).

Os sentimentos de punição estão entre os sentimentos enfrentados diariamente pelas pessoas com sofrimento mental. Desde sensação de que será punido ou que merece uma punição, até sensação de que deve punir-se por não conseguir realizar suas próprias expectativas e/ou sair da situação negativa que se encontra.

Segundo Cavalcante, Minayo e Mangas (2013), quando uma pessoa apresenta sintomas de depressão ela se sente punida em relação aos erros normais do seu cotidiano, e os sentimentos de culpa podem ser entendidos como uma barreira que afeta o fluir de determinadas situações ou responsabilidades.

Sentir-se culpado é uma sensação que as pessoas sentem com bastante frequência, e isso acarreta para caminhos depressivos. Em certa quantidade é natural da vida se sentir culpado por algo que não deu certo e isso ajuda a aprender com as vivências dolorosas a se adaptar a determinadas funções do cotidiano, em excesso torna-se patológico (LUCAS; ROMANO, 2015).

A sensação de culpa pelos erros ou até pela própria existência tornam-se, para alguns depressivos, obstáculos para a melhora do estado depressivo. Muitas vezes, a culpa pode estar 
relacionada à sensação de causa de prejuízo na vida de outras pessoas e pode ser justificativa para o fim da própria vida.

Um sinal de depressão realmente grave não desaparece de uma pessoa do dia pra noite, é normal no decorrer dos dias mais cansativos as pessoas pela manhã se sentirem sem prazer e sem força de vontade pra seguir com o dia (PURCORTES JUNIOR, 2012).

O trabalho pode ser responsável pelo sentimento de prazer ou sofrimento, tudo depende da forma que o profissional se organiza, a participação e colaboração entre ele e sua equipe (OLIVEIRA; MAZZAIA; MARCOLAN, 2015).

O desinteresse e perda de prazer estão relacionados a qualidade de vida e rotinas diárias. A partir disso, a grande influência do trabalho no bem estar geral do funcionário, tendo em vista que é o local onde passa-se a maior parte do tempo diário.

De acordo com Gomes (2011), todas as pessoas estão sujeitas a fracassar. Todos os dias temos que fazer escolhas, tomar atitudes e temos um objetivo pra viver melhor o que pode ser frustrado e nem sempre alcançamos nossas metas.

Com o autoconhecimento as pessoas podem pressupor seus possíveis fracassos e fazer ações para evitar erros futuros (COSTA et al. 2017).

Ter uma visão pessimista no trabalho sentir-se e interpretar o que o que se vive pelo lado negativo, presumindo sempre o pior de si e das pessoas em volta, o que acaba atrapalhando o crescimento profissional (CAVALCANTE et al. 2010).

Segundo Fernandes, Nascimento e Costa (2010), a depressão possui uma proporção multifatorial, seus sintomas podem aparecer por motivos influenciáveis de dentro pra fora ou de fora pra dentro, tendo como sintomas mais notáveis a tristeza, perda de prazer, fadiga, se sentir punido e ter pensamentos pessimistas.

O pessimismo geralmente está relacionado ao modo como se enxerga as situações. Ter uma visão sempre pessimista é desgastante e desestimulante, pois é impossível sentir-se feliz e com bem estar quando se depara com tudo negativo a sua volta e a partir daí, há o sofrimento psíquico e indícios depressivos.

Quando uma pessoa se depara com descontrole de sentimentos, em que a felicidade se torna difícil, a estima está esgotada, o ser está fadigado e há falta concentração engloba-se as sensações e denomina-se tristeza (RIOS; BARBOSA; BELASCO, 2010; ABELHA, 2014). 
Sentimentos negativos provocam tristeza e crises de choro, quando uma pessoa está deprimida e não consegue expressar guarda pra si todas suas angustias (GOMES, 2011).

$\mathrm{O}$ acúmulo de sensações e sentimentos desestimula e isola o indivíduo, deixando-o triste. A tristeza como sintoma que pode contribuir para a depressão traz consigo variados motivos internos, que não demandam uma força externa mas sim um desequilíbrio mental e incapacidade em ser feliz.

O IDB, de acordo com Vargas e Dias (2011), não deve ser analisado como diagnóstico de depressão, sendo necessária aplicação clínica concomitante. Contudo, o inventário é internacionalmente reconhecido por avaliar a intensidade de depressão, tendo valor preditivo em torno de $90 \%$.

De acordo com Koch et al. (2017), o IDB qualifica-se como instrumento de busca para detectar a frequência da depressão. Considera também que quando existem níveis de depressão mínimos pode haver manifestação de interesse por terapia para suporte psicológico diante as aflições da rotina.

Baseado nos resultados da presente pesquisa, 70\% dos participantes apresentaram depressão mínima, confirmando os estudos que avaliam a população de enfermagem hospitalar privado com baixo índice de depressão.

Conforme Gomes e Oliveira (2012) apesar de serem sintomas considerados leves e moderados, a existência desse índice comprova a tendência e suscetibilidade aos problemas psíquicos inerentes ao trabalho.

Fundamentado nas porcentagens obtidas, $30 \%$ dos profissionais demonstraram tendência leve a moderada à depressão. O que comprova a predisposição e sofrimento psicológico em enfermeiros, mesmo os que atuam no serviço hospitalar privado.

De acordo com as ideias de Costa et al. (2017), os cuidados fundamentais aos depressivos não se abreviam em medicações, envolve também detecção precoce, suporte social e terapias.

Contudo, os resultados nos mostraram a tendência depressiva dos profissionais enfermeiros. O que torna fundamental busca constante de melhores condições de trabalho, valorização, promoção de qualidade de vida e recuperação dos indivíduos adoecidos mentalmente e principalmente a necessidade de diagnóstico precoce. 


\section{Conclusão}

Os trabalhadores enfermeiros vivem diariamente momentos de extrema alegria ou tristeza e estão sempre sob pressão. Por vezes a expectativas de reversão é frustrada e naturalmente, há sofrimento e frustração do profissional.

Neste estudo, foi observado que, em maioria (70\%) os profissionais não apresentaram sintomas depressivos. No entanto, parte dos participantes tem de leve a moderada tendência depressiva, o que evidencia a relação de sofrimento psicológico dos profissionais de enfermagem à profissão em ambiente de hospital privado.

A pesquisa, apesar de número limitado de participantes, demonstrou resultados satisfatórios pois pode-se reafirmar a inclinação da enfermagem, atuante em hospital privado, à depressão.

Verifica-se a necessidade de outros estudos em ambientes privados pela escassa existência de materiais desse contexto. Portanto, novos estudos deverão ser realizados acerca desse assunto, a fim de conhecer a saúde psíquica do profissional enfermeiro e, através desses dados, definir estratégias para qualidade de vida e de trabalho.

\section{Referências}

ABELHA, L. Depressão, uma questão de saúde pública. Cad. Saúde Colet. v. 22, n. 3, p. 223, 2014.

ALMEIDA, L. N.; SILVA, J.; FÉLIX, A.; ROCHA, R. A. M. O suicídio no Brasil: Um desafio às Ciências Sociais.REBELA - Revista Brasileira de Estudos Latinos-Americanos. v. 5, n. 3. set./dez, 2015.

CAMARGO, R. M.; SOUSA, C. O.; OLIVEIRA, M. L. C. Reme prevalence of cases of depression in nursing students in an institution of higher education in Brasilia. Rev Min Enferm., v. 18, n.2, p. 398-403, abr./jun., 2014.

COSTA, T. S., MEDEIROS, R. C. de; SOUSA, M. N. A.; UCHIDA, R. R.; MIRANDA, F. A. N. Intensidade e sintomas depressivos em usuários da estratégia saúde da familia. Interfaces Científicas - Saúde e Ambiente. v. 5, n. 3, p.47-56, 2017.

CRUZ, B. S. P. Burnout e Fadiga por Compaixão em Enfermeiros Portugueses. 2014. 
DUAILIB, K.; SILVA, A. S. M.; JUBARA, C. F. B. Depressão. Rev. Bras. Med. v.72, n.12, p.40-41, 2015.

FERNANDES, D. M.; MARCOLAN, J. F. Trabalho e sintomatologia depressiva em enfermeiros da Estratégia de Saúde da Família. S mad. Revista Eletrônica Saúde Mental Álcool e Drogas (edição em Português). v. 13, n. 1, p.37-44, 9 fev. 2017.

FERREIRA, M.; FERREIRA, C. Carga mental e carga psíquica em profissionais de enfermagem. Revista Portuguesa de Enfermagem de Saúde Mental. ESPECIAL 1, abr. 2014.

FLEURYI, H. J.; ABDOII, C. H. N. Programa de Estudos em Sexualidade (ProSex) do Instituto de Psiquiatria do Hospital das Clínicas da Faculdade de Medicina da Universidade de São Paulo, Sexualidade da mulher idosa, Diagn. Tratamento. v. 20, n. 3, p. 117-120, 2015.

GARRO, I. M. B.; CAMILO, S. O.; NOBREGA, M. P. S. S. Depressão em Graduandos de Enfermagem. Acta Paul Enferm. v.19, n.2, p. 162-167, 2016.

GOMES, R. K.; OLIVEIRA, V. B. Depressão, ansiedade e suporte social em profissionais de enfermagem. Boletim de Psicologia. São Paulo, v. 63, n. 138, p.23-33, fev. 2013.

GUERREIRO, D. P. das N. V. Necessidade Psicológica de Auto-Estima/Auto-Crítica: Relação com Bem-Estar e DistressPsicológico. 114 f. Dissertação (Mestrado) - Mestrado Integrado em Psicologia. Faculdade de Lisboa, 2011.

KOCH, M. O.; ZAMIAN, R.; VICTOR, G. L. G.; SEGURA, D. C. A. Depressão em pacientes com câncer de mama em tratamento hospitalar. Saúde e Pesquisa. Maringá, v. 10, n. 1, p.111117, abr. 2017.

LUCAS, M. G.; ROMANO, R. Assédio moral nas relações de trabalho: implicações psicológicas. ReCaPe - Revista de Carreiras e Pessoas São Paulo. v. 5, n. 3, Set./Out./Nov./Dez., 2015.

MARQUETTI, F. C.; MILEK, G. Percurso suicida: observação e análise de alterações no cotidiano do indivíduo com tentativas de suicídio. Rev. Ter. Ocup. Univ São Paulo.v. 25, n. 1, jan/abr., 2014.

MOLL, M. F.; ELIAS, B. A. B.; GOMES, B. F.; SILVA, L. D.; SANTOS, L. F. R. J Depressão infantil na ótica dos professores do ensino fundamental. Nurs Health, v. 4, n. 2, p. 135-142, 2014.

NARDI, P. C.; FERREIRA, I. M. F.; NEUFELD, C. B. Resultados preliminares do Programa PRHAVIDA em crianças com escores clínicos de ansiedade, depressão e estresse. Contextos Clínicos. v. 10, n. 1, p.74-84, 2017. 
NAVARRO, M. C. C.; MARTÍNEZ, M. C. P. Atitudes do profissional de enfermagem em relação ao comportamento suicida: influência da inteligência emocional. Rev. Latino Am. Enfermagem, v. 20, n. 6, nov./dez., 2012.

OLIVEIRA. F. P.; MAZZAIA, M. C.; MARCOLAN, J. F. Sintomas de depressão e fatores intervenientes entre enfermeiros de serviço hospitalar de emergência. Acta Paul Enferm. v. 28, n. 3, p. 209-215, 2015.

OLIVEIRA, J. D. O. et al. Representações sociais de enfermeiros acerca do estresse laboral em um serviço de urgência. Rev. Esc. Enferm. USP. v.47, n.4, p. 984-989, 2015

ORGANIZAÇÃO INTERNACIONAL DO TRABALHO - OIT. Centro de informações.

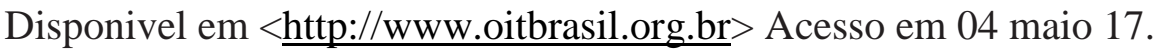

PRETO, V. A.; PEDRÃO, L. J. A percepção de enfermeiros de unidades de terapia intensiva sobre o estresse em seu local de trabalho. Revista de enfermagem, v. 8, n.9, p. 2998-3007, 2014.

PROYER, R. T.; SIDLER, N.; WEBER, M., \& RUCH, W.A multi-method approach to studying the relationship between character strengths and vocational interests in adolescents.International Journal for Educational and Vocational Guidance. v. 12, n. 2, p. 141-157, 2012.

PURCOTES JÚNIOR, F. O simbolismo da depressão na perspectiva junguiana. Psicol. Argum. n. 30, v. 71, p. 613-620, out./dez. 2012

RIBEIRO, R.P.; MARTINS, J.T.; MARZIALE, M.H.P.; ROBAZZI, M.L.C.C. O adoecer pelo trabalho na enfermagem: uma revisão integrativa. Rev Esc Enferm USP. v.46, n.2, p.495-504, 2012.

SANTOS, A. S.; MONTEIRO, J. K.; DILÉLIO, A. S.; SOBROSA, G. M. R.; BOROWKI, S. B. V. Contexto hospitalar publico e privado: impacto do adoecimento mental de trabalhadores da saúde. Trabalho, Educação e Saúde. v. 15, n. 2, p.421-438, ago. 2017.

SANTOS, O. S.; MAIO, A. P.; BARBOSA, C. B. B.; SOUZA, J. M. V.; SIMÕES, A. P. E. Depressão infantil: sintomas e aspectos sociais, psicológicos na educação escolar. Revista da Educação. v. 16, n. 1, p. 47-60, jan./jun., 2016.

SANTOS, W. A. Uma reflexão necessária sobre a profissão docente no brasil, a partir dos cinco tipos de desvalorização do professor. Sapere Aude - Belo Horizonte. v. 6, n.11, p. 349$358-2^{\circ}$ sem., 2015.

SCHULTHEISZ, T. S. de V.; APRILE, M. R. Autoestima, conceitos correlatos e avaliação. Revista Equilíbrio Corporal e Saúde. v. 5, n. 1, p. 36-48, 2013.

SEMEDO, D. C.; VENTURA, J.; PAULA, D. F.; SILVA, M. R. S.; PELZER, M. T. Fatores associados a depressão e os cuidados de enfermagem no idoso. Revista de enfermagem. v.12, n.12, p. 101-113, 2016. 
SILVA, N. C.; FERREIRA, J. V. B.; ALBUQUERQUE, T. C.; RODRIGUES, M. R.; MEDEIROS M. F. Transtornos à saúde mental relacionados à intensa rotina de trabalho do enfermeiro: uma revisão bibliográfica. Revista Eletrônica Estácio Saúde. v. 5, n. 2, 2016.

VARGAS, D.; DIAS, A. P. V. Prevalência de depressão em trabalhadores de enfermagem de Unidade de Terapia Intensiva: estudo em hospitais de uma cidade do noroeste do Estado São Paulo. Rev. Latino-Am. Enfermagem.v.19, n.5, 2011.

VEGRO, T. C.; ROCHA, F. L. R.; CAMELO, S.H.H.; GARCIA, A. B. Cultura organizacional de um hospital privado. Revista Gaúcha de Enfermagem. v. 37, n. 2, p.1-6, 2016. FapUNIFESP

WANG, Y.; GORENSTEIN, C.Psychometricpropertiesofthe Beck DepressionInventory-II: a comprehensivereview. Revista Brasileira de Psiquiatria. v. 35, n. 4, p.416-431, dez. 2013.

ZANDONÁ, C.; CABRAL, F. B.; SUlZBACH, C. C. Produtivismo acadêmico, prazer e sofrimento: um estudo bibliográfico. Perspectiva, Erechim. v. 38, n. 144, p. 121-130, dezembro/2014.

\section{Como citar este artigo (Formato ABNT):}

LUZ, Alisson Aparecido da; LIMA, Denise de F.; BORGES, Amanda Aparecida; PEREIRA, Vanessa O. S. ; ALVES, Mateus Goulart ; DALRÍ, Maria Celia B. Sintomas Depressivos em Enfermeiros do Serviço Hospitalar Privado. Id on Line Revista Multidisciplinar e de Psicologia, 2018, vol.12, n.41, p.169-191. ISSN: 1981-1179.

Recebido: 04.06.2018

Aceito: 14.06 .2018 